Revista Brasileira de Meteorologia, v.27, n.2, 119 - 126, 2012

\title{
ZONEAMENTO DOS DESASTRES NATURAIS OCORRIDOS NO ESTADO DO RIO GRANDE DO SUL NO PERÍODO 1989 - 2009: GRANIZO E VENDAVAL
}

\author{
ANDERSON NEDEL, TANIA M. SAUSEN, SILVIA M. SAITO \\ Universidade Federal de Santa Maria, Centro Regional Sul de Pesquisas Espaciais, Santa Maria, RS, Brasil. \\ asnedel@gmail.com, tania@1tid.inpe.br, silvia.saito@crs.inpe.br
}

Recebido Julho de 2010 - Aceito Dezembro de 2011

\begin{abstract}
RESUMO
Esse estudo tem por objetivo realizar um zoneamento das ocorrências de granizo e vendaval no estado do Rio Grande do Sul (RS), entre os anos 1989 e 2009. Foram utilizados os registros de ocorrências dos eventos (com e sem decretação de situação de emergência), obtidos junto à Coordenadoria Estadual de Defesa Civil do RS (CEDEC), a fim de analisar o período de maior freqüência de ocorrências e as regiões mais atingidas por esses eventos. Os resultados mostraram que, em relação aos eventos de granizo a estação mais favorável para sua ocorrência é a primavera (290 eventos), seguida do inverno (132 eventos). As áreas que apresentaram as maiores ocorrências localizaram-se na metade norte do Estado, dentre as quais se destacaram como mais atingidas o Alto Uruguai (217 eventos) e Planalto Médio (90 eventos). As regiões da Depressão Central e das Missões também foram bastante atingidas por tais tempestades, porém com uma freqüência ligeiramente menor ( 83 e 70 eventos). Com relação aos vendavais, as regiões mais afetadas foram as do Alto Uruguai (271 eventos), Planalto Médio (120), Depressão Central (116) e Missões (96 eventos), e o período de maior ocorrência foi a primavera (novembro e outubro). Regiões como o Litoral (24), Encosta do Sudeste (13) e Serra do Sudeste (11) registraram poucos episódios durante os vinte anos estudados, o que caracteriza a porção Sul do estado como a menos preferencial a esses extremos de tempo. Foi mostrado também, que esses eventos adversos não acontecem somente em anos com a presença dos fenômenos climáticos El Niño e La Niña. Houve ocorrências de intensos episódios em anos classificados como neutros (ausência dos fenômenos).
\end{abstract}

Palavras chaves: Desastres Naturais, Granizo, Vendaval

ABSTRACT: MAPPING OF NATURAL DISASTERS ON RIO GRANDE DO SUL STATE DURING 1989 TO 2009: HAILS AND WIND STORMS

This paper aims to carry out a mapping of wind storms and hails natural disasters occurred in Rio Grande do Sul state during the period from 1989 to 2009. Records of the events were obtained at the State Civil Defense Authority to analyze the preferential period for these occurrences and the most affected areas by these events. The results showed that most of the hails occurred in spring (290 events) and in winter (132 events), and the most affected regions were Alto Uruguai (217 events) and Planalto Médio (90 events). The regions of Depressão Central and Missões were also affected, but with a slightly lower frequency ( 83 and 70 events). Regarding to wind storms, the most affected areas were those located in the northern half of the state: Alto Uruguai (271 events), Planalto Médio (120), Depressão Central (116) and Missões (90), and the highest occurrence were observed in the spring season (preferential period), in the months November and October . In the Sea Shore, Southeast coast and Southeast mountains regions few episodes of hails and wind storms have occurred (24, 13 and 11 events respectively), characterizing the south region of the State as the most improbable region for the occurrence of these extreme events. It was also found that hail and wind storms did not occur only in years with presence of the El Niño and La Niña climatic events. They also occurred in periods without the influence of these phenomena (normal years).

Keywords: Natural Disasters, Hails, Wind Storm 


\section{INTRODUÇÃO}

Durante as últimas décadas várias partes do mundo vêm enfrentando alterações em suas características climáticas. Tanto no Hemisfério Sul (HS), quanto no Hemisfério Norte (HN), não apenas exemplos de degelo, mas também de elevação significativa do nível do mar, intensas precipitações, estiagens severas em regiões normalmente úmidas, processos de desertificação, ondas de frio e calor, entre outros, têm sido cuidadosamente estudados pela comunidade científica como fenômenos associados, principalmente, ao aquecimento global.

A ocorrência de desastres naturais no Brasil tem exigido permanente atenção dos órgãos de defesa civil nos últimos anos. Eventos extremos de tempo, como tempestades de granizo, vendavais, enchentes e enxurradas, secas, e deslizamentos de terras têm castigado o país, e ocasionado danos à sociedade, afetando milhares de pessoas, principalmente nos últimos três anos (Figura 1). A região Sul do país, principalmente, composta pelos estados do Paraná (PR), Santa Catarina (SC) e Rio Grande do Sul (RS) tem sofrido muito com a intensidade destas adversidades. Segundo as notificações (decretos) das coordenadorias estaduais e municipais de defesa civil (CEDEC e CODEC), o Rio Grande do Sul é o estado que tem sido mais afetado por estes eventos. As Figuras 2a e 2b mostram a ocorrência de desastres naturais na Regiao Sul do Brasil e os eventos de granizo e vendaval nos três Estados.

Entre os principais sistemas atmosféricos que influenciam as condições de tempo no Rio Grande do Sul (RS), favorecendo a ocorrência de desastres naturais, podem-se citar os sistemas frontais (frentes frias), as convecções locais (devido ao aquecimento diurno da superfície) e os sistemas convectivos de mesoescala (SCM). Em uma escala espaço - temporal maior (grande escala, com centenas e milhares de $\mathrm{km}$, e da ordem de meses e anos) o Estado também é influenciado pelos fenômenos climáticos El Niño e La Niña, os quais são caracterizados pelo

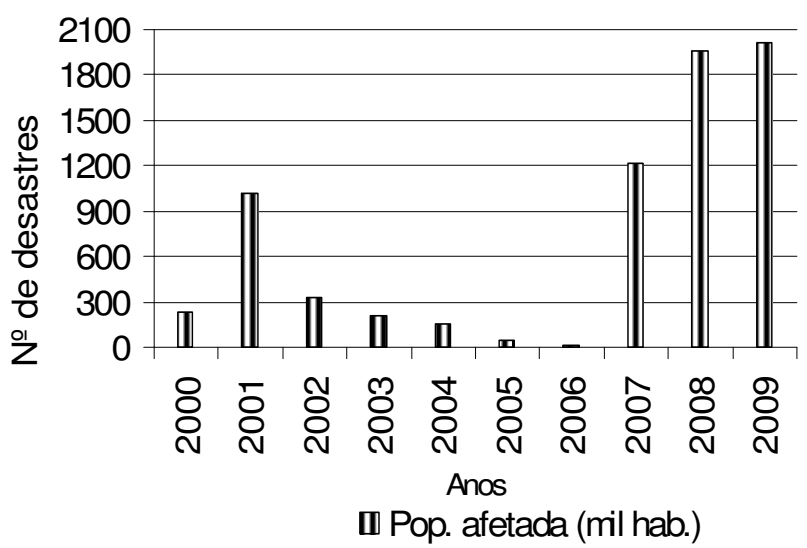

Figura 1 - População afetada por desastres naturais ocorridos no Brasil entre os anos 2000 e 2009. Fonte: EMDAT. aquecimento e resfriamento das águas do oceano Pacífico Equatorial, respectivamente, determinantes para a ocorrência de severos episódios de secas e inundações.

Os SCM e as Frentes Frias são os principais responsáveis por tempestades intensas (vendaval e granizo) no Rio Grande do Sul durante a primavera e o verão. Analogamente para Santa Catarina, segundo Marcelino et al. (2004), que estudando a climatologia do granizo naquele Estado mostraram haver maior freqüência de tempestades durante a primavera (sobretudo nos meses de outubro e novembro). Os autores observaram que estas estavam relacionadas, principalmente, aos Complexos Convectivos de Mesoescala (CCMs).

De acordo com Maddox (1980) e Madox et al (1982), os CCM são um tipo especial de Sistema Convectivo de Mesoescala (SCM). São áreas de instabilidades que freqüentemente estão associadas a eventos de tempo severo na América do Sul. Formam-se sobre o Paraguai e região norte da Argentina, e tem como característica grande extensão espacial (centenas de milhares de kilômetros) e tempo de vida maior que 6 horas. Anabor (2008) afirma que SCM são verificados sobre a região sul da América do Sul com tempos de vida superiores a 18 horas (alguns com até 72 horas), principalmente durante a primavera e verão.

O objetivo deste trabalho é analisar os eventos de vendaval e granizo ocorridos no estado Rio Grande do Sul entre 1989 e 2009, verificar as regiões mais afetadas por esses episódios e os períodos mais favoráveis para suas ocorrências.

\section{MATERIAIS E MÉTODOS}

Foram utilizadas nesse estudo as informações das ocorrências de eventos de vendaval e granizo no Rio Grande do Sul no período 1989 a 2009, obtidas da Coordenadoria Estadual de Defesa Civil (CEDEC), a qual é notificada pelos municípios atingidos pelos episódios, através dos relatórios de Avaliação de Danos (AVADAN) cuja intensidade pode fazê-los decretar Situação de Emergência ou estado de Calamidade Pública: $\mathrm{SE}, \mathrm{CP}$. Isso mostra que os eventos de granizo e vendaval apresentados neste trabalho tiveram grandes proporções e ocasionaram enormes prejuízos aos municípios do Estado.

Os dados foram organizados em tabelas de acordo com o tipo de evento e a data de ocorrência, com o intuito de analisar a sua freqüência (mensais e anuais) e os períodos em que estes mais ocorreram (mais favoráveis a sua recorrência). $\mathrm{O}$ período de início e término de cada estação do ano para fins de classificação das ocorrências de granizo se baseou nas seguintes datas: Outono, 20/03 a 19/06; Inverno, 20/06 a 21/09; Primavera, 22/09 a 20/12 e verão, 21/12 a 19/03.

Foram também verificadas as regiões mais afetadas por granizo e vendaval e os municípios mais atingidos, ao longo 
(a)

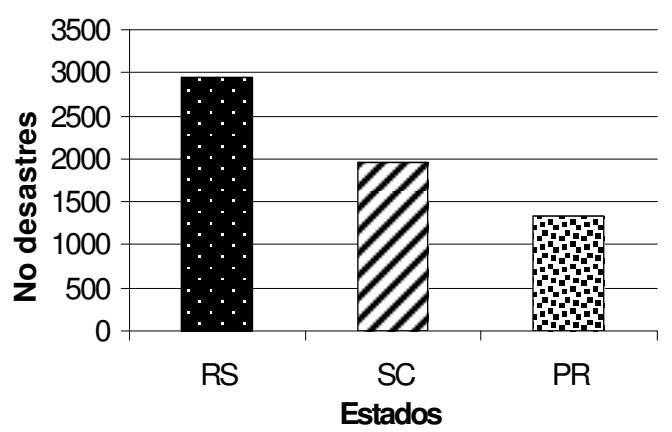

(b)

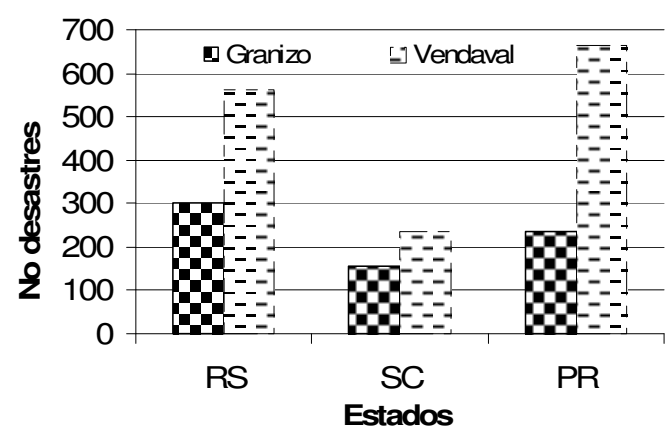

Figura 2 - Número de desastres naturais ocorridos na regiao Sul do Brasil entre os anos 2000 e 2009 (a), e os eventos de granizo e vendaval ocorridos nos três estados da região (b). Fonte: Defesa Civil, RS, SC, PR.

dos vinte anos de análise. Os municípios que compreendem o RS foram classificados (nas regiões) utilizando o mapa das regiões fisiográficas, que divide o Estado em 11 regiões. Suas ilustrações nas figuras foram realizadas através do software Spring, versão 5.0 (Camara et al, 1996). A Figura 3 mostra o mapa fisiográfico do RS utilizado para classificar os municípios onde ocorreram os eventos.

\section{RESULTADOS E DISCUSSÃO}

As regiões preferenciais de ocorrências dos eventos de granizo (a) e vendaval (b) no Rio Grande do Sul entre os anos 1989 e 2009 são mostradas nas Figuras 4 a 9. Dentre os eventos ocorridos, os vendavais foram os que ocasionaram o maior número de notificações, segundo a defesa civil, afetando maior quantidade de municípios (787 decretos de situação de emergência), enquanto que os eventos de granizo atingiram um número menor de localidades, (levando a 563 notificações), de acordo com os registros da CEDEC.

\section{(a) Granizo}

A Figura 4 apresenta a distribuição temporal da ocorrência de granizo ao longo dos anos, associada ao número de decretos de SE registrados pelos municípios do RS, durante os vinte anos analisados (1989/2009). Nota-se que a estação preferencial para as ocorrências foi a primavera onde 290 decretos foram registrados, seguida do inverno onde houve 132 registros. Na mesma figura se observa também, que as ocorrências dos eventos durante a primavera são maiores, inclusive, que a soma de todas as ocorrências das outras estações do ano (273 decretos) (Figura 4a).

Outro ponto que merece destaque é que em todos os meses do ano, o estado do RS foi afetado por episódios de granizo. Outubro (184 decretos) e novembro ( 80 decretos) foram os meses com maior registro de episódios, e março (10 decretos) e junho (9 decretos) os meses em que menos episódios se registraram (Figura 4b). Esses resultados corroboram com aqueles apresentados por Berlato et al. (2000) que, analisando a ocorrência de granizo no Rio Grande do Sul, mostrou a primavera como sendo a estação preferencial para ocorrência desses eventos e março (outono) como o mês (estação) de menor ocorrência. Segundo Cunha et al. (2001) a maior incidência de granizo na primavera (e final do inverno) ocorre devido, principalmente, a atuação de SCM associados à passagem dos sistemas frontais pelo RS, mais intensas neste período. Na mesma linha segue Silva Dias (1996), que afirma que as ocorrências de granizo nos meses de outubro e novembro estão mais relacionadas com a presença de CCMs. Esses sistemas são áreas de instabilidades que se formam sobre o Paraguai e no Norte da Argentina (região do Chaco), e que se deslocam em direção ao oceano passando sobre os estados de SC e RS.

A Figura 5 mostra a distribuição espacial dos eventos de granizo no estado do Rio Grande do Sul (RS). Essas tempestades foram observadas em todas as regiões. As áreas que apresentaram as maiores ocorrências localizaram-se na metade norte gaúcha, dentre as quais se destacam como mais atingidas as regiões do Alto Uruguai (217 decretos) e Planalto Médio (90 decretos), que juntas representam a metade dos eventos ocorridos nos sete anos analisados. Espacializando mais esses eventos, nota-se que regiões como a Depressão Central (83 decretos) e as Missões (70 decretos) também foram atingidas por tais tempestades, porém com ocorrência ligeiramente menor.

A Figura 6 apresenta a distribuição anual dos eventos de granizos entre 1989 e 2009. Observa-se que os episódios mais intensos foram os eventos ocorridos em 1997, 1998 e 2007, afetando vários municípios gaúchos, 83, 53 e 50, respectivamente. Em 1997, ano de El Niño de forte intensidade, o RS teve por característica apresentar eventos extremos de tempo (precipitações acima da média, episódios de granizo e vendaval intensos, principalmente durante a primavera, 


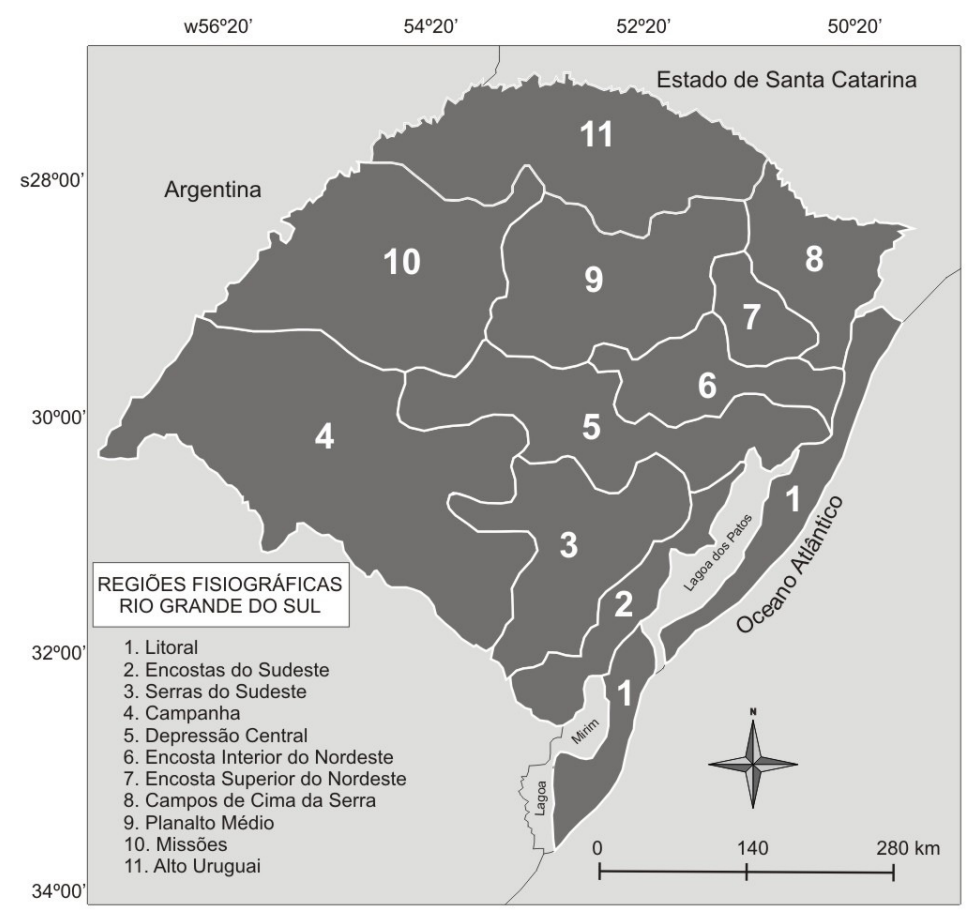

Figura 3 - Regiões fisiográficas do Rio Grande do Sul. Fonte: SEMA/RS.

(a)

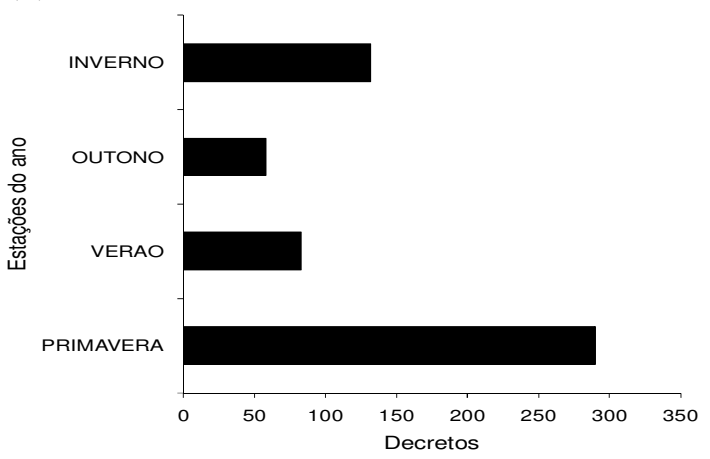

(b)

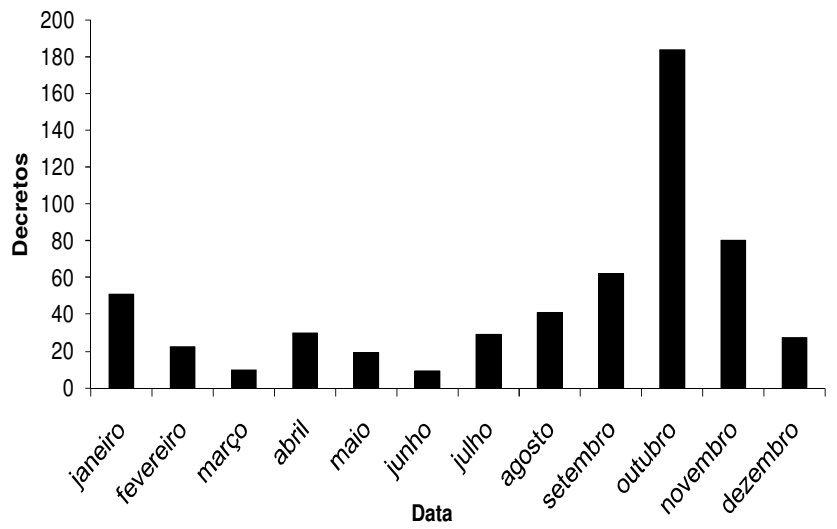

Figura 4 - Número de ocorrências de granizo no RS durante as estações do ano (a) e ao longo dos meses do ano (b), entre 1989 a 2009.

conforme mencionado anteriormente). Nesse ano, foram 29 municípios em situação de emergência no mês de outubro e 36 em novembro. Merece destaque também o ano de 2007, quando 33 dos 67 municípios que foram atingidos por eventos de granizo, decretaram situação de emergência pelo mesmo evento meteorológico: uma tempestade de granizo ocorrida em 20 de outubro de 2007. Ou seja, a mesma condição meteorológica ocasionou prejuízos em diversas localidades durante sua trajetória. Seu deslocamento foi de noroeste-norte (NO-N), e os municípios mais afetados nesse episódio foram aqueles localizados nessas regiões.

Os impactos causados pelos eventos El Niño e La Niña (El Niño Oscilação Sul - ENOS), no Rio Grande do Sul, são amplamente conhecidos e vêm sendo estudados por vários pesquisadores nos últimos anos. Segundo Grimm e Tedeschi (2006) a ocorrência de eventos extremos de precipitação na região Sul do Brasil está relacionada a episódios ENOS com certas condições particulares (oscilações interdecadais do 


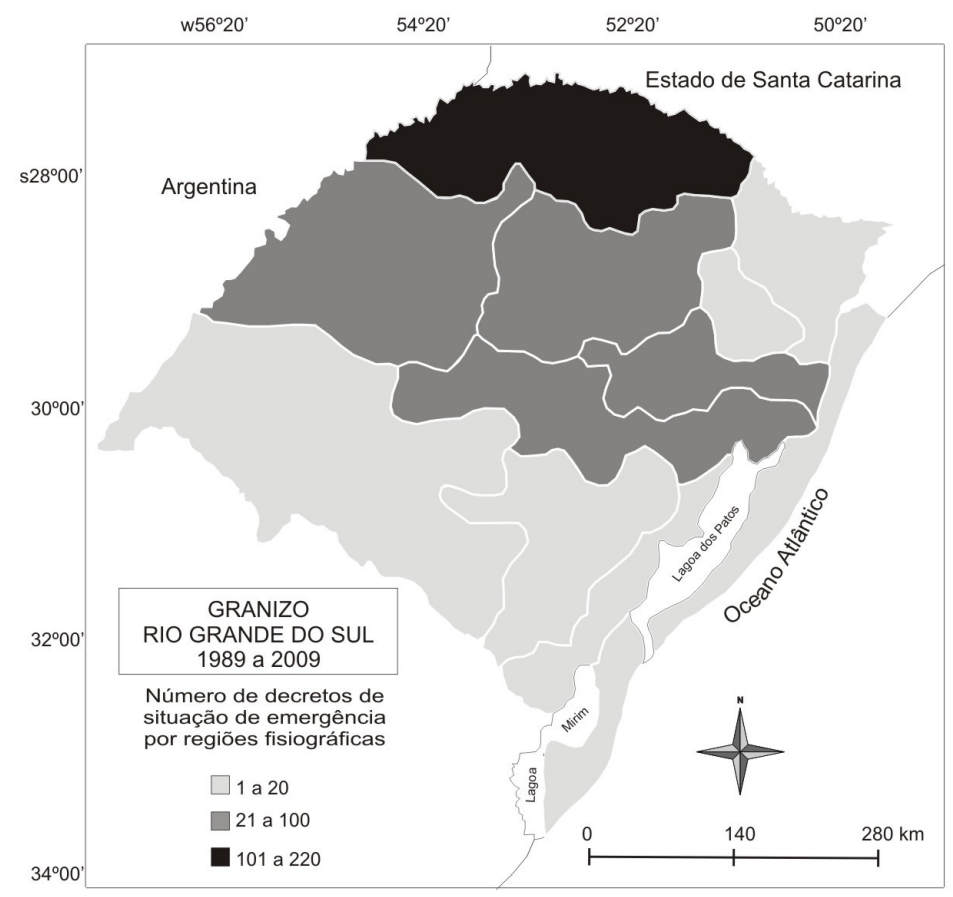

Figura 5 - Regiões atingidas por granizo no Rio Grande do Sul no período 1989 a 2009.

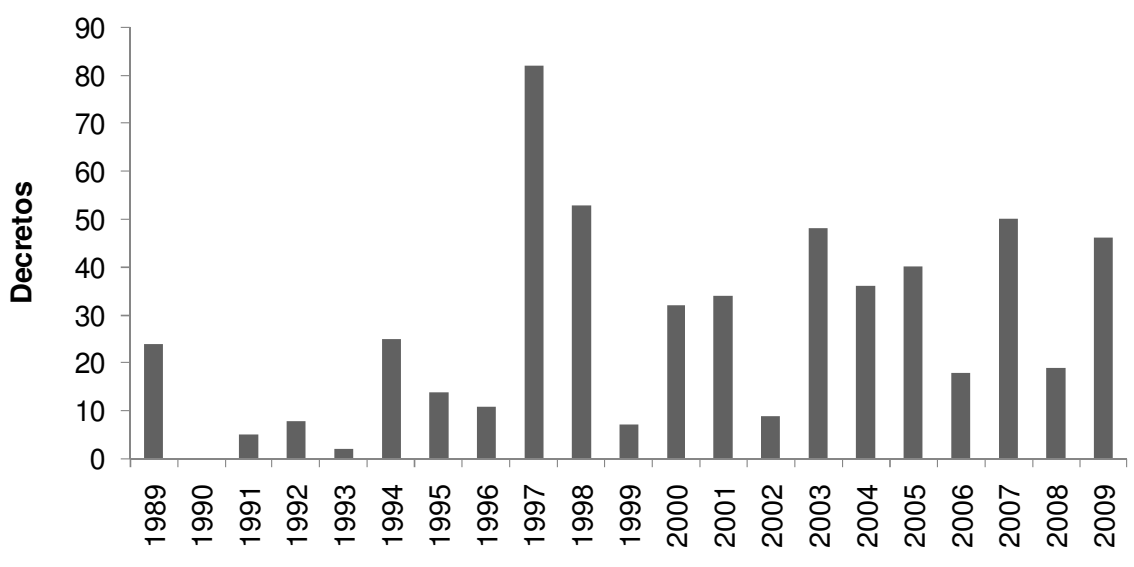

Data

Figura 6 - Episódios registrados de granizo no estado do Rio Grande do Sul, no período 1989 a 2009.

fenômeno) e aumenta ou diminui de acordo com as anomalias de circulação atmosférica associada. Marcelino et al. (2004) afirma que a variação anual das ocorrências severas de granizo pode estar associada com o fenômeno ENOS. Segundo este autor, para a Região Sul do Brasil, o El Niño interfere na intensificação do jato subtropical em altos níveis da atmosfera, que intensifica os sistemas frontais transientes em superfície, bloqueando-os sobre a região. Para um estudo realizado em Santa Catarina, verificou-se um maior número de registros de granizo, quando comparado sua frequência anual de ocorrência com anos ENOS.

O granizo é um fenômeno meteorológico que se desenvolve em nuvens de tempestades de grande desenvolvimento vertical, chamadas Cumulonimbus (Cb), compostas por uma ou por várias células convectivas (Supercélulas) geradoras de instabilidades. Pode ser considerado como um evento extremo de tempo (Marcelino, 2003). Seu desenvolvimento se dá nas partes mais elevadas das nuvens, acima da linha de zero grau (temperaturas da ordem de $-25^{\circ} \mathrm{Ce}-30^{\circ} \mathrm{C}$ ), quando as gotículas de água superresfriadas se congelam e são transformadas em gelo.

Observando todos os eventos ocorridos entre 1989 e 2009 (Figura 6), pode-se constatar também baseados nos decretos de situação de emergência dos municípios, que não há uma tendência clara de aumento (de forma linear) desses eventos ao longo desse período, embora haja um evidente aumento 
dos desastres naturais (inundações, estiagens, vendavais, deslizamentos de terra, etc...). O que parece haver com os eventos de granizo são oscilações nas intensidades e ocorrências desses eventos, com eventos bastante intensos em determinado ano e outros com menor intensidade em anos seguintes.

\section{(b) Vendaval}

Observando a Figura 7 nota-se que, assim como para os casos de granizo, a estação preferencial para ocorrência de vendavais no estado do RS foi a primavera (429 decretos), seguido das estações de verão (171 decretos) e outono (100 decretos). Nota-se que a ocorrência destes eventos durante a primavera é mais que três vezes o número de eventos ocorridos

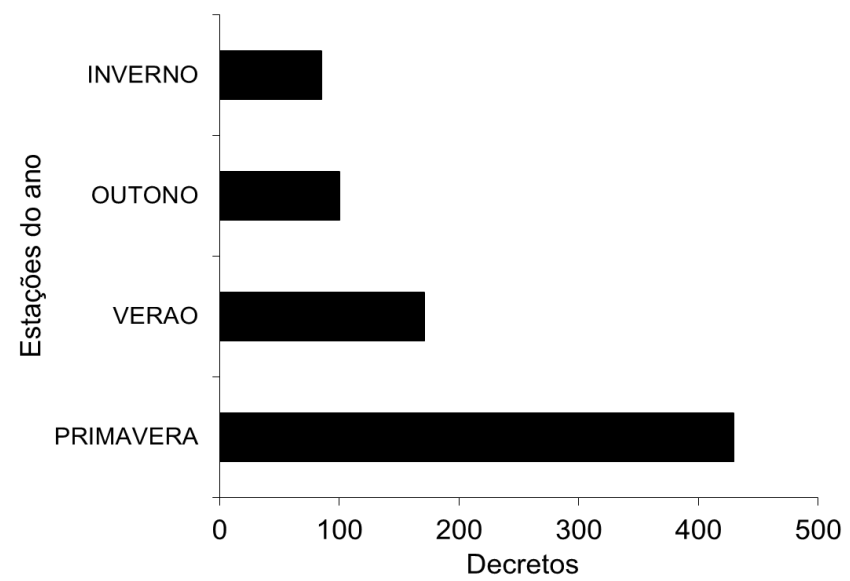

em outras estações (verão e inverno) (Figura 7a). Torna-se evidente o aumento destes eventos a partir dos meses de inverno, até a primavera, quando estes atingem seu pico (de ocorrência), diminuindo nos meses subsequentes (verão, outono e inverno). A figura também mostra que os vendavais afetaram o Rio Grande do Sul durante o ano todo. Novembro (199 decretos) e outubro (163 decretos) foram os meses em que os municípios mais sofreram com essas adversidades, e junho e julho foram os meses que menos episódios foram registrados (23 decretos) (Figura 7b).

A Figura 8 mostra a distribuição espacial dos vendavais nas diferentes regiões do RS. Esses eventos (decretos) também foram observados em todas as regiões do estado gaúcho. As

Figura 7 - Número de ocorrência de vendaval no RS durante as estações do ano (a) e ao longo dos meses do ano (b), entre 1989 a 2009.

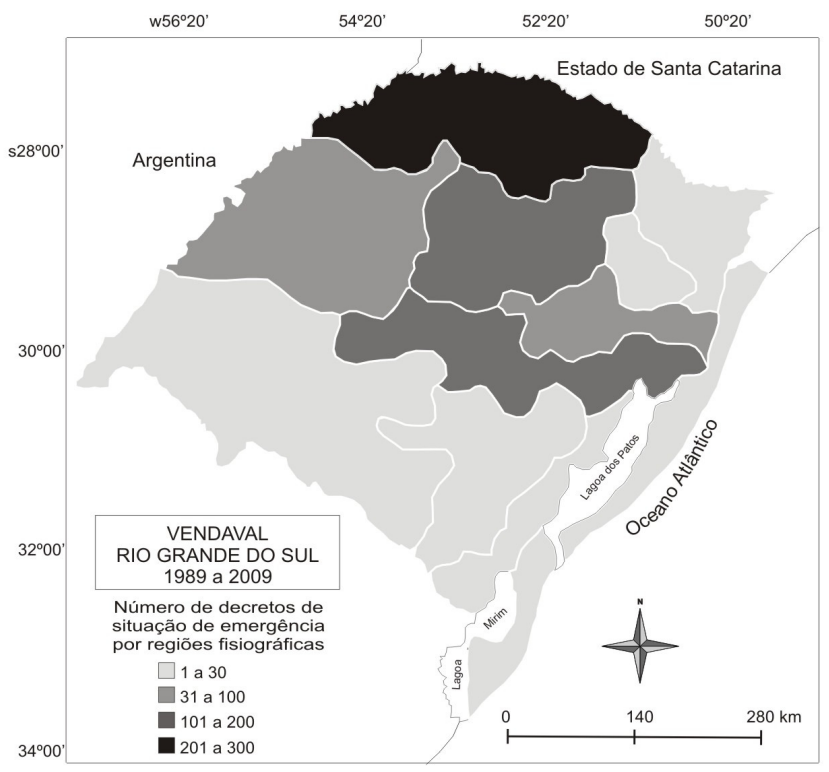

Figura 8 - Distribuição espacial dos vendavais no Rio Grande do Sul, período 1989 a 2009. 
áreas que apresentaram as maiores ocorrências localizam-se na metade norte, sendo mais afetadas as regiões do Alto Uruguai (271 decretos), Planalto Médio (120 decretos), Depressão Central (116 decretos) e Missões (96). Nesse contexto, ao considerar as regiões do Alto Uruguai e o Planalto Médio gaúcho observa-se aproximadamente a metade das ocorrências de vendavais do RS. Entretanto, regiões como o Litoral (24), a Encosta do Sudeste (13) e a Serra do Sudeste (11) registraram poucos episódios (decretos) durante os 20 anos estudados, o que caracteriza a porção Sul do estado como menos favorável a essas adversidades.

A Figura 9 apresenta os vendavais registrados pelos municípios do Rio Grande do Sul. Observa-se uma maior ocorrência de eventos nos anos de 2009 (140) e 2003 (127), que se somados representam $35 \%$ dos vendavais ocorridos ao longo de todo o período no Estado. $\mathrm{O}$ ano com episódios mais intensos foi 2009. A maioria dos decretos por situação de emergência foi registrada nos meses de novembro (71) e dezembro (23), quando o estado do Rio Grande do Sul estava sob a influência do El Niño 2009-2010 (moderado). O segundo ano, com maiores danos ocasionados por vendavais, foi 2003. Somente no mês de outubro foram enviados 49 decretos. Embora possa existir uma relação entre anos de $E l$ Niño e episódios intensos de granizo (Marcelino et al., 2004), o mesmo não pode ser esperado para eventos de vendaval.

Da mesma maneira que para os eventos de granizo, não há uma clara evidência de aumentos de suas ocorrências, ao longo dos últimos 20 anos. O que se observa são períodos (não muito bem definidos) de aumento seguido de períodos de diminuição de ocorrências e tudo varia, de acordo com a série temporal (número de anos) que se utilizar. Por exemplo, quando se observa os últimos 5 anos, nota-se, em geral, uma diminuição dos eventos granizo, com exceção do ano de 2009, que foi o ano onde mais ocorrências foram registradas.

\section{CONCLUSÕES}

Este estudo analisou a distribuição de eventos de granizo e vendaval, causadores de desastres naturais no Rio Grande do Sul (RS), quantificando as regiões do Estado mais atingidas e os períodos mais favoráveis para suas ocorrências. Foi mostrado que ambos os eventos (granizo e vendaval) ocorreram ao longo do ano todo, sendo suas maiores ocorrências registradas durante a primavera. Considerando a distribuição espacial destes eventos nas diferentes regiões fisiográficas do RS notou-se que, tanto para granizo, quanto para vendaval, as regiões do Alto Uruguai e do Planalto Médio Rio-Grandense foram as mais atingidas, apresentando danos (prejuízos) devido a estes eventos. Em termos de distribuição temporal, episódios mais intensos de granizo ocorreram nos anos 1997, 1998 e 2007 e os maiores registros de danos por vendavais ocorreram nos anos de 2009 e 2003, mostrando não haver uma relação de intensidade clara entre ambas as adversidades, de maneira que, anos de eventos de granizos intensos não coincidiram com anos de vendavais intensos, embora o maior número de decretos de SE por granizo e vendavais se registrassem nos anos de 1997 e 2009, quando o estado estava sob a influência do fenômeno El Niño (1998/1998, de intensidade forte e 2009/2010, de intensidade moderada).

Foi possível também notar ao longo nos 20 anos analisados (1989 a 2009), que não há uma tendência evidente de aumento destas adversidades. O que existe são períodos (aleatórios) de aumentos e diminuições dos episódios, que acabam por atingir a população gaúcha com maior ou menor intensidade. Sugere-se, devido à importância desse tipo de estudo, a continuidade deste trabalho através da análise de uma série histórica maior de dados ( $\geq 30$ anos, p.e.) utilizando com seleção mais criteriosa dos eventos, a fim do comprovar os resultados já encontrados, bem como, se existe relação com

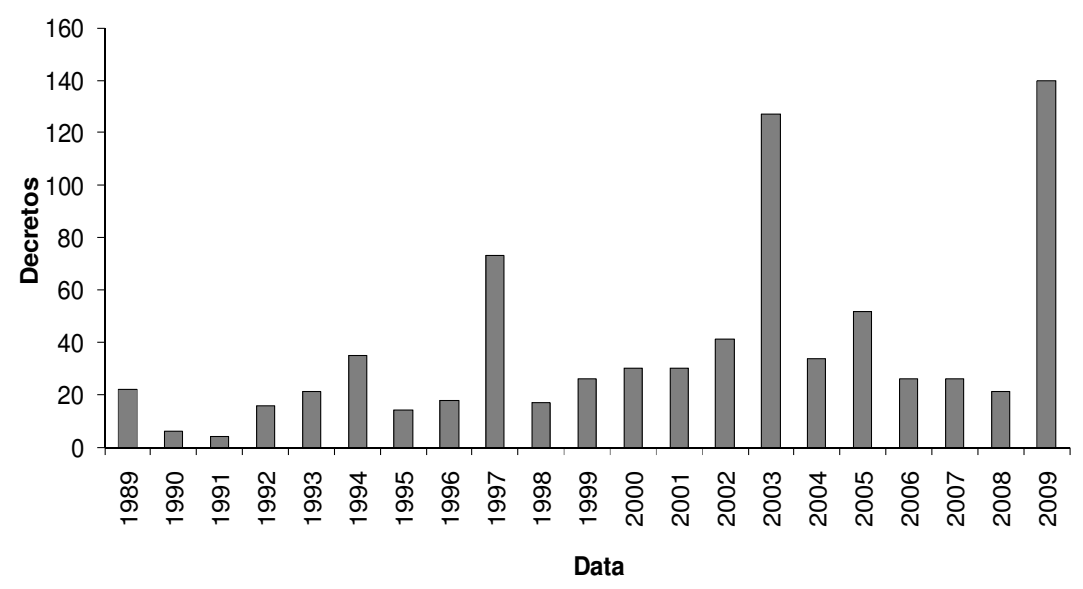

Figura 9 - Distribuição temporal dos vendavais no Rio Grande do Sul, no período 1989 a 2009. 
ENOS. Tais resultados se mostram de grande utilidade para atuar na prevenção e mitigação de danos ocasionados por esses eventos naturais.

\section{REFERÊNCIAS BIBLIOGRÁFICAS}

ANABOR, V.: Sistemas convectivos de mesoescala no sul da América do sul: propagação em série contra o escoamento em baixos níveis. Tese de doutorado. Universidade Federal de Santa Maria, 2008.

BERLATO, M. A.; MELLO, R. W.; FONTANA, D. C.: Risco de ocorrência de granizo no estado do Rio Grande do Sul. Revista Brasileira de Agrometeorologia, Santa Maria, RS, v.8, n.1, p 121-132, 2000.

CAMARA, G.; SOUSA, R.C.M.; FREITAS, U.M., GARRIDO, J.: SPRING: Integrating Remote Sensing and GIS by ObjectOriented Data Modelling. Computers and Graphics, vol. 15, n.6, 1996.

COORDENADORIA ESTADUAL DE DEFESA CIVIL, CEDEC, Disponível em www.defesacivil.rs.gov.br. Acessado em 22 de maio de 2010.

CUNHA, G. R.; SCHEEREN, P. L.; SÓ, S. M., : Granizo e Cereais de Inverno no Rio Grande do Sul. Embrapa / Trigo, Passo Fundo, RS, 24p, 2001.
GRIMM, A. M.; TEDESCHI, R. G.: Episódios EL NIÑO e LA NIÑA e a freqüência de eventos extremos de precipitação no Brasil: análise no litoral da região sul. XV Congresso Brasileiro de Meteorologia, Florianópolis, SC, 2006.

MADDOX, R. A: Mesoscale convective complexes. Bulletin of the American Meteorological Society., vol. 61, pp. 1374-1387., 1980.

MADDOX, R. A.; ROGERS, D. M.; HOWARD, K. W.: Mesoscale convective complexes over the United States during 1981 - An annual summary. Monthly Weather Review, 110, 1501-1514, 1982.

MARCELINO, I. P. V. O.: Análise de episódios de tornados em Santa Catarina: caracterização sinótica e mineração de dados. Dissertação (Mestrado em Sensoriamento Remoto) - Instituto Nacional de Pesquisas Espaciais, São José dos Campos. 214 p, 2003

MARCELINO, I. P. V. O.; MENDONZA,M.; RUDORFF. F. M.: Ocorrências de granizo no estado de Santa Catarina. Simpósio Brasileiro de Desastres Naturais vol. 1, p.795805 (CD-ROM). Florianópolis, 2004.

SILVA DIAS, M. A. F. Complexos convectivos de mesoescala. In: Climanálise Especial: edição comemorativa de 10 anos. Cachoeira Paulista: CPTEC/INPE, p. 173-182, 1996. 